\title{
Attention, short-term memory, and academic performance
}

\author{
B. L. KINTZ \\ Western Washington State College, Bellingham, Washington 98225
}

\begin{abstract}
In order to evaluate the relationship between attention and academic performance, 132 novel Russian-letter trigrams were used as stimuli. Each was presented for 2 sec, then one of 132-response-recognition quadrigae of trigrams, containing the previously shown stimulus trigram and 3 foils was shown for $2 \mathrm{sec}$. S's task was to choose the correct response trigram from among the quadriga. Large differences in performance occurred, depending upon which element of the trigram was varied in the response quadrigae. An interaction between the varying element in the trigram and the position of the particular trigram within the overall list also occurred. Correlations between performance on this task and the academic performance of the students were all essentially zero.
\end{abstract}

The amount of immediate recall of visual stimuli depends upon the two mechanisms of attention and memory. The studies of Peterson and Peterson (1959), Murdock (1962, 1963), Melton (1963), and of Kintz (1965) show that as time between stimulation and recall increases, the amount recalled rapidly decreases. Schneider and Kintz (1967) showed that instructions which directed Ss' attention to various stimulus characteristics affected control over the amount of material the Ss recalled on an incidental learning task: The more direct the attention, the better the recall.

The present investigation is concerned with an attempt to determine the degree to which attention is related to long-term recall. Short-term recall was measured by presenting novel stimuli to a group of students and asking them to choose the stimulus they had just seen from among four stimulus trigrams shown together. Indirect measures of long-term retention were obtained from eight measures of academic performance. The basic hypothesis was that better attention would be positively correlated with higher academic achievement.

\section{METHOD}

\section{Subjects}

Seventy-one college students enrolled in an introductory course served as Ss. Eight measures of academic aptitude and performance, including high school GPA and first quarter college GPA, were obtained for 43 of the Ss. Not all of the academic measures were available for the other Ss.

\section{Materials}

One hundred and thirty-one stimulus trigrams were prepared on white $5 \times 8$ index cards. Twelve letters of the Russian alphabet, chosen because they are distinctively different in appearance from letters of the English alphabet, were used as the first and third letters of the trigrams. Four letters (looking like the English vowels $\mathrm{A}, \mathrm{E}, \mathrm{O}$ and the letter $\mathrm{Y}$ ) were used as the middle letter of the trigrams. Each Russian letter appeared 11 times as the first letter, and 11 times as the third letter tut the same letter was never used as both first and third letters in the same trigram. Each middle letter appeared 33 times, appropriately intermixed with the Russian-letter members of the trigrams.
Then, 132 quadrigae of trigrams were prepared such that one of the four trigrams on a card was exactly like the trigram on the matching stimulus card. The position of the matching (correct) trigram, among the other three of each quadriga, was counterbalanced so that there were no position cues. The quadrigae were constructed in such a way that $1 / 3$ of the 132 (44) were differentiated by having only the first letter of each trigram vary. Example: Using English letters--If the stimulus were DEX, the quadrigae might be: LEX, QEX, DEX, and WEX. Another $1 / 3$ had the third letter as the variable: DEQ, DEV, DES, and DEX; while the final $1 / 3$ had the second letter as the variable: DEX, DAX, DOX, DYX.

\section{Procedure.}

The 132 sets of stimuli and quadrigae were numbered, then stacked into a pile according to a table of random numbers, with the restriction that nearly the same proportion of first-letter-varying, second-letter-varying and third-letter-varying sets were in the consecutive thirds of the deck. The resulting deck is represented by Table 1 .

Ss received a short verbal introduction explaining the general purpose of the experiment. Then, the instructions for the experiment were given, and a sample set of cards, using geometric shapes, was used to demonstrate. Each $\mathrm{S}$ was given an IBM multiple-choice answer sheet on which to record his responses. Since the quadrigae served essentially as foils for the stimulus trigram "question," the use of the IBM answer sheets was easily understood by the students.

Each stimulus card was shown for $2 \mathrm{sec}$; then, immediately, the appropriate quadriga was shown for $2 \mathrm{sec}$. S's task was to attend to the stimulus trigram and try to remember it long enough to pick its mate from among the quadriga of trigrams presented immediately after. They then marked the answer on the appropriate place on the answer sheet. The cards were numbered so that $\mathrm{E}$ could periodically remind Ss which answer they were working on at that time.

\section{Table 1}

Number of Trigrams with the Particular Letter Varying that Appeared in Each Third of the List

\begin{tabular}{lllccr}
\hline & & \multicolumn{4}{c}{ Trigram Letter that Varied } \\
\cline { 3 - 5 } & & 1st & 2nd & 3rd & \\
\hline Position in 132 & 1st & 13 & 15 & 16 & 44 \\
Items by Thirds & 2nd & 17 & 13 & 14 & 44 \\
& 3rd & 14 & 16 & 14 & 44 \\
& & 44 & 44 & 44 & 132 \\
\hline
\end{tabular}




\section{RESULTS}

\section{Scoring}

A scoring key was punched and the number of correct responses counted for each S. One of the 71 Ss had only 31 correct out of 132 possible. This appeared to be indicative of just guessing so it was decided to set a criterion to throw out probable guesswork. Since right-wrong is a dichotomy, with the probability of guessing correctly on any card equal to $1 / 4$, the expected number of correct responses by guessing is $1 / 4(132)=33$. The standard deviation of such guesswork would be $\sqrt{ } 33(3 / 4)=4.97$. Since three standard deviations above the chance level would include nearly all the answer sheets that represent strictly guesswork, that value was chosen. Thus, the data for any $S$ who didn't get more than 48 correct out of 132 were discarded. The data for six Ss were eliminated using this criterion. This report will consider the data for the 65 remaining Ss, 40 of whom were female and 25 of whom were male. All of the Ss said they had never studied the Russian language.

\section{Sex and the Trigram Element That Varied}

The data were counted again, recording for each $S$ the number of correct responses when a particular element of the trigram was the variable. Figure 1 represents the data for males and females and the element of the trigram that was varied. The apparent small sex difference is well within the range of chance variation $(\mathrm{F}=.79)$. The difference due to the element variable is quite large $[F(2,126)=53.66, p<.0001]$. Each element group mean is different from the other two $(p<.0001)$ using Sheffé's stringent test for multiple comparisons. Thus, when the third element was the variable Ss performed best; when the first element varied, they performed next best; and when the middle element varied, they performed most poorly. These data are interpreted as showing the amount of attention the Ss

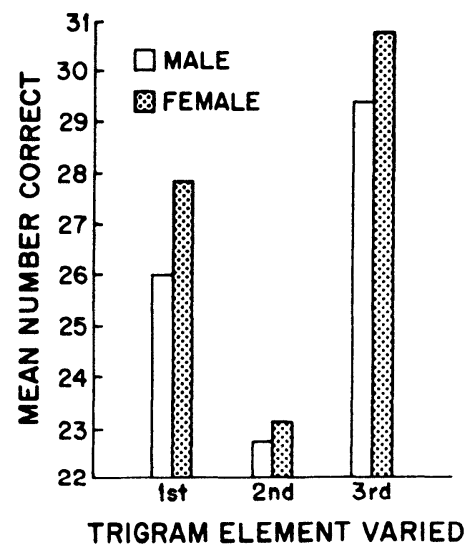

Fig. 1. Mean number correct (masimum possible $=44$ ) as a function of sex of the $S$ and the element of the trigram that varied.

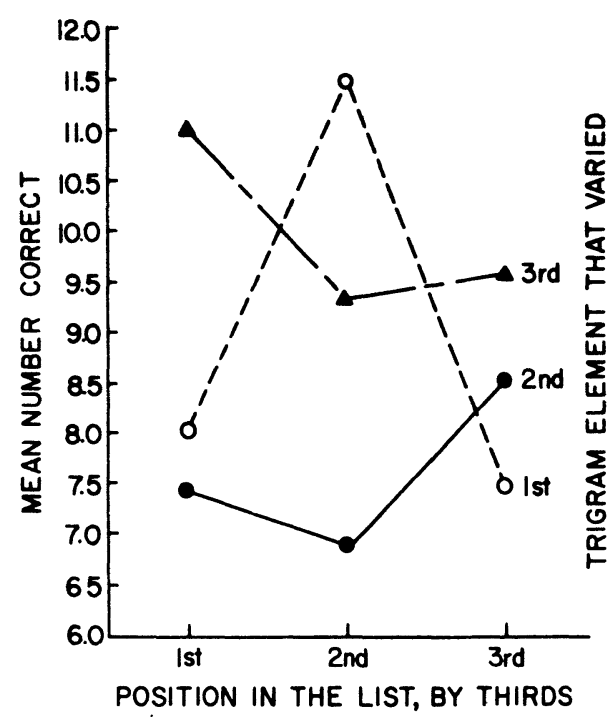

Fig. 2. Mean number correct (maximum possible $=17$ ) as a function of the variable element of the trigram, and the order in the list.

paid to the various elements. This is the short-term retention when the retention interval is very short.

Trigram Element Varied and Position in List of Trigram

There is a possibility that as Ss were moving along through the 132 items they tried different problem-solving strategies. To test for this possibility the data were counted again, this time recording the number correct for each one-third of the 132 sets of cards (first, second and third third-parts, respectively).

Figure 2 represents the data according to which element of the trigram varied, and the position in the overall list. Depending upon which element of the trigram varied, there is the difference as presented in Fig. 1. The position of the material within the list also produced differences exceeding the chance level $[F(2,64)=5.23, p<.007]$. The data of Fig. 2 indicate that early in the experiment the third element of the trigram produced the highest level of correct responses. Later, in the middle of the experiment, the first element produced the highest number of correct responses. And finally, toward the end of the experiment, the third element again became preeminent, but the second element exceeded the first in producing correct responses.

\section{Correlations With Academic Variables}

Eight measures of academic aptitude and peformance were available for 43 of the 65 Ss $(25$ female and 18 male). The eight measures were named: (1) first quarter college freshman GPA; (2) high school GPA; (3) vocabulary usage; (4) total English; (5) predicted mathematics score; (6) verbal aptitude; (7) reading speed and $(8)$ reading comprehension. None of these variables 
correlated with overall performance on the Russian trigram task above the chance level (the correlations varied around zero). A multiple correlation computed using all eight measures as predictors, and the total correct on the Russian trigram task as the criterion, also was within the chance range. Thus, whatever skills are needed to perform well on this short-term memory task, they are not correlated with these measures of academic aptitude and performance.

Since the students had performed differently on the alphabet task depending upon which element of the trigram varied, correlations were run comparing the eight academic variables and the three trigram elements. The correlations among the eight variables were substantial in size as were the correlations among the three trigram elements, but again there were no correlations that differed significantly from zero between any of the trigram elements and any of the academic variables. This suggested that the short-term retention tasks were tending to cluster together and that the long-term retention indices belonged to an entirely different cluster.

A factor analysis of the eight variables produced three factors that accounted for $73 \%$ of the total variance. After Varimax rotation the clusters were clearly of three identifiable groups: (1) the short-term retention measures; (2) the GPA and predicted math scores and (3) all five of the verbal and reading scores.

\section{DISCUSSION}

\section{Academic Learning and Russian Trigram Task}

One reason for the lack of relationship between the success scores on the present task and the academic measures is provided by considering the distinction between short-term retention and long-term retention. Traditional academic success depends largely upon learning the material sufficiently well that it will be retained for a considerable period of time. The achievement test normally follows the initial acquisition by several hours, and often by many days or weeks. The present task, as well as the typical short-term memory task, required Ss to attend to stimuli and immediately to make a discriminative response. Thus, the emphasis is upon immediate recall and no actual learning need take place. The present data can be interpreted as an example of a clear-cut distinction between immediate recall of a sensory event as contrasted with long-term recall that involves material learned well enough to perseverate over a considerable period of time. Not only are the two kinds of memory distinguishable in a rehetorical sense, but the present results suggest that high ability on immediate memory tasks is unrelated to ability level on several academic indices of long-term retention.

\section{REFERENCES}

Kintz, B. L. Short-term retention and long-term retention as a function of practice. The Journal of Psychology, 1965, 59, 309-314.

Melton, A. W. Implications of short-term memory for a general theory of memory. Journal of Verbal Learning \& Verbal Behavior, 1963, 2, 1-21.

Murdock, B. B., Jr. Direction of recall in short-term memory. Journal of Verbal Learning \& Verbal Behavior, 1962, 1, 119-124.

Murdock, B. B., Jr. Short-term retention of single paired associates. Journal of Experimental Psychology, 1963, 65, 433-443.

Peterson, L. R., \& Peterson, M. J. Short-term retention of individual verbal items. Journal of Experimental Psychology, 1959, 58, 193-198.

Schneider, F. W., \& Kintz, B. L. An analysis of the incidental-intentional learning dichotomy. Journal of Experimental Psychology, 1967, 73, 85-90.

(Received for publication July 29, 1974.) 